\title{
Power Quality Disturbances of Electrified Railway
}

\author{
Abdulrahman A. Bajandooh \\ Center of Research Excellence in Renewable Energy and \\ Power Systems \\ Deptartment of Electrical and Computer Engineering \\ Faculty of Engineering \\ King Abdulaziz University \\ Jeddah 21589, Saudi Arabia
}

ORCID: 0000-0003-0244-7327

\author{
Muhyaddin J. Rawa \\ Center of Research Excellence in Renewable Energy and \\ Power Systems \\ Deptartment of Electrical and Computer Engineering \\ Faculty of Engineering \\ King Abdulaziz University \\ Jeddah 21589, Saudi Arabia
}

\begin{abstract}
Transportation is one of the biggest energy consumers, especially automobiles. In a world where energy conservation and environmental issues are growing concerns, the development of electric vehicle technology has taken on an accelerated pace. Electrified railway system has big advantages to save energy, environmental factor and mass capacity compare with their rivals for example automobiles and aircrafts. Therefore, the electrified railway has increased its share and importance on transportation system during the last twenty years. However, railway systems have many power quality problems. The aim of this paper is to study the effects of electrified railway systems on power system quality. Moreover, solutions to mitigate these problems will also be discussed and assessed.
\end{abstract}

Keywords: Power Quality, Railway, Traction Power, Harmonics, Unbalance voltage, Reactive power.

\section{INTRODUCTION}

Both electrical utilities and end users are becoming increasingly concerned about the quality of electric power. The term "Power Quality" has become one of the most prolific buzzwords in the power industry since the late 1980s. It is an umbrella concept for a multitude of individual types of power system disturbances. The issues that fall under this umbrella are not necessarily new. What is new that engineers are now attempting to deal with these issues using a system approach rather than handling them as individual problems [1].

There are four major reasons for the increased concern:

1. Newer-generation load equipment, with microprocessorbased control and power electronic devices, is more sensitive to power quality variations than was equipment used in the past.

2. The increasing emphasis on overall power system efficiency has resulted in continued growth in the application of devices such as high efficiency, adjustable-
ORCID: 0000-0001-6035-5733

speed motor drives, and shunt capacitors for power factor correction to reduce losses. This is resulting in increasing harmonic levels on power systems and has many people concerned about the future impact on system capabilities.

3. End users have an increased awareness of power quality issues. Utility customers are becoming better informed about such issues as interruptions, sags and switching transients and are challenging the utilities to improve the quality of delivered power.

4. Many things are now interconnected in a network. Integrated processes mean that the failure of any component has much more important consequences [1].

The ultimate reason that we are interested in power quality is economic value. There are economic impacts on utilities, their customers, and suppliers of load equipment. For example, in 2006 the Leonard Power Quality Initiative presented a study of PQ impact on the European industry, claiming that this type of problem caused losses of over $€ 150$ billion [2].

The "Power Quality Disturbances" definition is:

Any power problem manifested in voltage, current or frequency deviations that results in failure or misoperation of customer equipment [1].

The improving of power quality and specially in railway industry is very important due to mentioned reasons above and since this industry is growing up in Kingdom of Saudi Arabia, here is the list of electrified railway projects but not limited to [3]:

1- Haramain Highspeed Railway (HHR).

2- Northern Train.

3- Arriyadh Metro.

4- Almashaer Metro.

5- Makkah Metro. 


\section{PROBLEM STATEMENT}

One of the Saudi Vision goal is to develop the transport sector and harnessing its absorptive capacity to meet all the requirements needed. The contribution of the transport sector is concentrated in removing the physical, legal and administrative obstacles to motivate the economic growth in the relevant sectors [3].

Transportation has a big share in energy consumption especially in case of automobiles. Railway is suitable for regular mass transportation and it is remarkably energy saving in comparison with its rivals, i.e. automobiles and aircraft. It holds an advantageous position in the field of commuter transportation, medium-distance passenger transportation within three hours and heavy haul as large as ten thousand tons. Shifting transportation media from trucks and automobiles to railways is very important to settle future energy and environmental issue.

The electrified railway load is one of the worst kinds of load for an electrical utility to supply. The only load which gives more challenge to the utility is arc furnace load. The electrified railway load is highly intermittent, irregular, low load factor and poor power factor. The railway electrification load creates system voltage and current unbalance, generates harmonics and results in voltage flicker. Because of the above characteristics the railway electrification load generally requires oversized substation facilities. It stresses the electrical utility equipment more and also causes interference with other customer loads and often complaints from the other utility customers, etc.

Electrified railway development has placed the rail transportation in a competitive position among transportation industries, due to its higher capacity, more reliable operation, less air pollution and less local $\mathrm{CO} 2$ generation.

There have been more impact load (electrified railway) in power system, the impact load will cause distortion of voltage and current waveform which may cause additional losses and high temperature, harmonics voltage and current distortion which may affect the operation stability of power system and also the voltage unbalance is one of the major disturbances in power system. On the other hand, one of the main reasons of power quality disturbances is when the three-phase power system connecting to single-phase traction power system (AC railway).

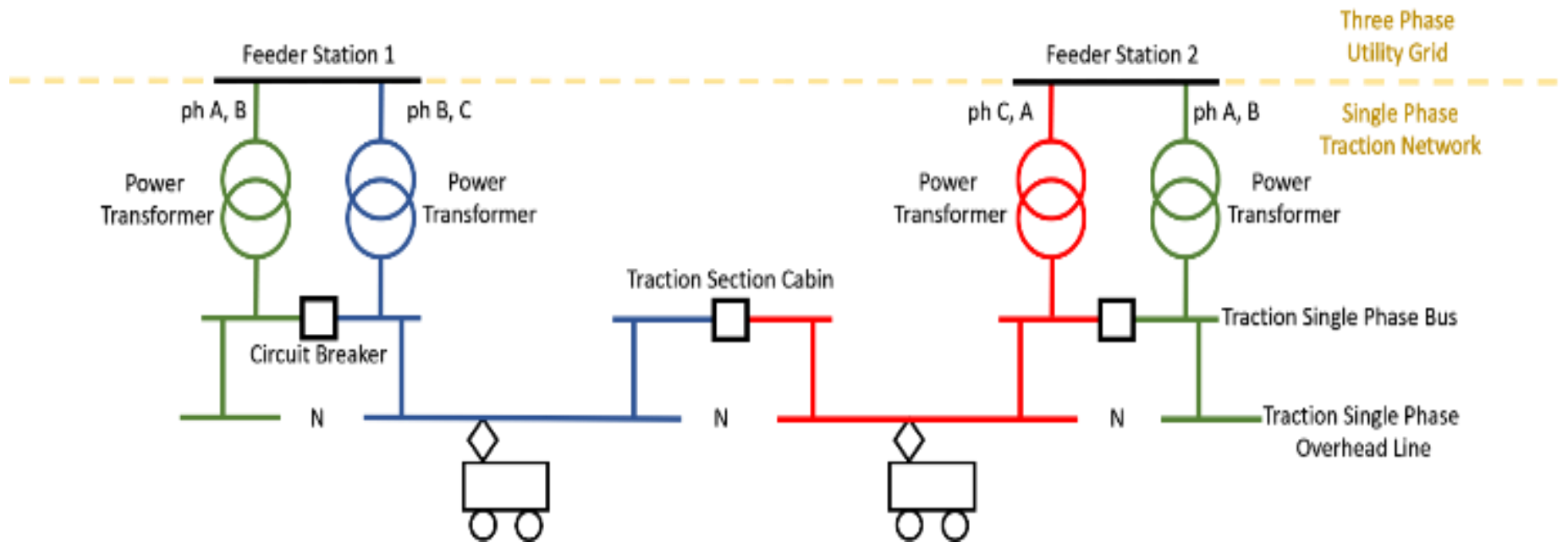

Figure 1: Traction Supply Network for AC Electrified Railway

\section{- $\quad$ Power Quality Phenomena in Electrified Railway}

1- Voltage / Current unbalance

System imbalance is the most serious problem in electric railway power quality because most trains are single phase and a single-phase load produces a current a negative-sequence component (NSC) as much as a positive-sequence component PSC and since a traction load is large (e.g., 5-20 MW), it may harm the power system and must be compensated [9].

\section{2- Harmonics}

Urban dc traction systems using 12-pulse rectifiers generate large amounts of the 11th and 13th order harmonics, and for ac traction systems, trains use ac/dc/ac converters causing different harmonics flowing into the three-phase power system [4].

\section{3- Reactive Power}

A low power factor value indicates a high amount of reactive power, which is an amount of the exchanged energy between the power supply substation and the reactive part of traction power substation. The reactive power is necessary for the traction system operation, but it should be reduced as much as possible to reduce the operation costs of the electrified railway [5].

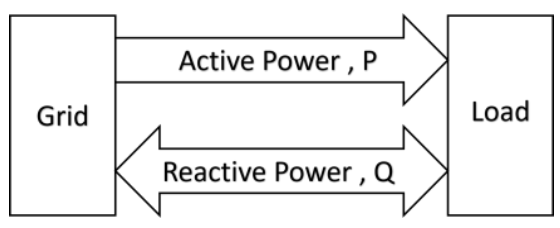

Figure 2: Reactive Power

4- Low-frequency voltage fluctuation

The most frequent problems of voltages are associated with their magnitudes. As noted, unbalanced currents produce unbalance voltage. Traction motors and other related loads are designed to 
function properly with reduced voltage amplitude by $24 \%$ or increased amplitude by $10 \%$ than the nominal voltage of electric railroad drives based on IEC-6850 and EN-50163 [4].

This may lead to increase the power losses and heating the wires of the contact network which leads to a loss of their mechanical strength.

\section{5- Voltage arcing}

Voltage arcing is partially unavoidable problem in electrified railway, and it is normally more predominant at high-speed trains. These phenomena occurs because of the interaction between the pantograph and the overhead line or between the brushes and the third/fourth rail. The main reason of the voltage arcing in the electrified railway is the varied airgaps due to the train mechanical oscillations [5].

In particular, on section isolators of overhead systems or ramps of the third/fourth rail, arcs will occur which can distort voltages and currents.

\section{- Impacts on various systems}

The degraded power quality of rail systems may result in the malfunction of nearby systems. The most important hazard of power quality shortcomings applies to upstream power supply networks that can be harmed. Furthermore, it may harm the operation of the signaling and communication systems of the railway. The impact of low power quality of traction systems on other systems are as follow:

\section{- Impacts on Electric Power Systems}

\section{1) Decreased utilization factor}

Since the traction load is a large single-phase load, it results in high current Negative sequence components (NSCs), which will flow in only two phases and it decreases the utilization factor of the transmission line.

\section{2) Malfunction of protection system}

Protection relays may operate incorrectly in the presence of harmonics and Negative sequence components (NSCs) of currents and voltages. Traction load injects a large amount of harmonics and NSCs, resulting in the malfunction of the protection system.

\section{- Impacts on signaling and communication systems}

The circuits of communication and signaling systems are designed to operate at a high frequency (higher than the fundamental frequency), different from the power fundamental frequency to avoid any possible interference. However, if the power system suffers from a high harmonic ratio, the high-order harmonic frequencies may disturb the communication signals, resulting in incorrect values and a fault in train monitoring, which could lead to a catastrophe. The voltages arcs are the main reason for the stray currents. However, and since the communication cables usually lie in parallel close to the power cables, the stray currents may generate magnetic fields in the communication cables and induce voltages that pollute the communication signal.

\section{- Impacts on electric locomotives}

The Negative sequence components (NSCs) of current will induce double frequency currents in the rotors surface of the induction motors used in traction. Consequently [15], this may increase the rotor temperature and it will harm the machine at the long-term use. On the other hand, the NSCs of currents can create a magnetic flux in the rotor that opposes the main rotation direction, whereby the torque produced by the traction motors will be reduced. In addition, and since the induction motors torque value is proportional to the square value of the applied RMS voltage, any voltage oscillations will directly be reflexed on the torque characteristics of the induction motors.

\section{CASE STUDY}

There are a lot of DC-AC electric locomotives which are main harmonic sources of traction network. The voltages of power system are distorted and power quality decline since the existence of harmonics to the power gird and other users are threatened. There are a lot of challenges in terms of quality in our life style (Power Quality is one of the main example) and the result of that it was necessary to develop the transport system in order to meet this challenge [6].

The traction system composed of AC-DC and AC-DC-AC traction which is causing a lot of problems in the network. The major problem of traction is the harmonics that produced by the traction due to the nonlinearity nature of the traction system. These harmonics are injected into the utility side which have a large influence on the power quality of the utility power system network. Also, it is fed from a single-phase AC voltage about $25 \mathrm{KV}$ which causes a several unbalance in the 3 -phase power system.

The electric traction is considered as a dynamic load because it is varying its position all the time during the journey. Also, the speed of the train is changing with the time according to the operation conditions. The power electronics elements, like thyristor and IGBT are playing a very important role in the controlling process of the traction speed. The control process is accomplished by controlling the firing angle of the thyristor or IGBT in order to control the voltage which will be applied on the traction [7].

The case study has been taken from practical railway system of high speed train with speed Rail 300 kilometers per hour.

It's designed to operate on a $25 \mathrm{kV} / 60 \mathrm{~Hz}$ catenary system, within the limits defined in the EN 50163. i.e., the traction system is designed to operate at $60 \mathrm{~Hz} \pm 1 \%$. 


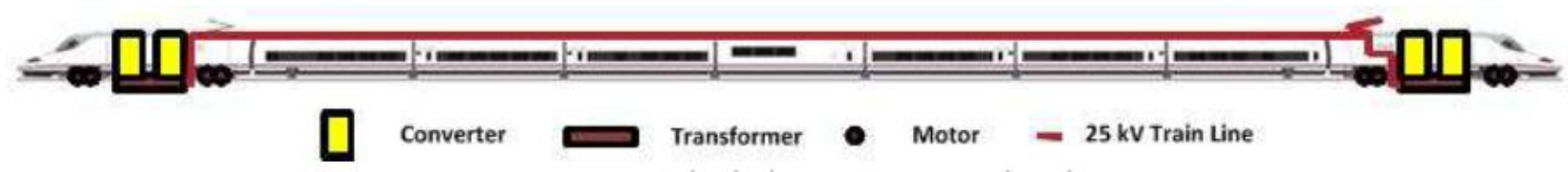

Figure 3: Block Diagram of Train

\section{Main components of the traction power system:}

\section{1- Traction Transformer}

A traction transformer is a large single-phase transformer fitted in the locomotive to feed power to traction motors and other auxiliaries. It takes $25 \mathrm{kv}$ AC from overhead line as primary voltage. This voltage is then stepped down and fed to a rectifier.

The main reason for $25 \mathrm{kv}$ voltage used in railway that is more economical, since $25 \mathrm{kv}$ voltage system has higher voltage to reduce the current flow through conductor, this reduce the conductor size.

\section{2- Traction Converter (AC/DC)}

Traction Converter has multiple line converters which convert single phase AC input to a stable DC link bus voltage. A combination of one or more inverters converts this DC bus voltage to 3-phase power controlling one or more traction motors each.

\section{3- Inverters (DC/AC)}

The second major component of the induction motor traction drive is the inverter system which converts the dc voltage that is output from the converter to ac power to drive the induction motors.

AC induction motor drives now compare favorably to DC motor drives in the aspects of power to weight ratio, acceleration performance, control flexibility, and maintenance. We adopted induction motors as driven power.

\section{4- Induction Motor}

A 3-phase squirrel cage induction motor is a type of three phase induction motor which functions based on the principle of electromagnetism. It is called a 'squirrel cage' motor because the rotor inside of it. One big advantage of a squirrel cage motor is how easily you can change its speed-torque characteristics. This can be done by simply adjusting the shape of the bars in the rotor. Squirrel cage induction motors are used a lot in industry as they are reliable, self-starting, and easy to adjust.

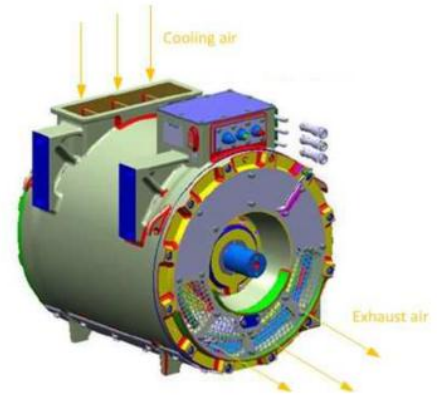

Figure 4: Induction Motor

\section{SIMULATION MODEL}

The proposed model is simulated by PSCAD/EMTDC. PSCAD is a powerful electromagnetic time domain transient simulation environment and study tool Such a complex model like railway system can be developed and simulated easily by using PSCAD/EMTDC [11] and due to quick response time of program, the simulation of the electric locomotive model under the different working sections and operation conditions can be realized in short time period.

The model has been adopted to establish the simulation in order to analyze and study the behavior of the traction power system [12] and its impact on power quality of the power supply system.

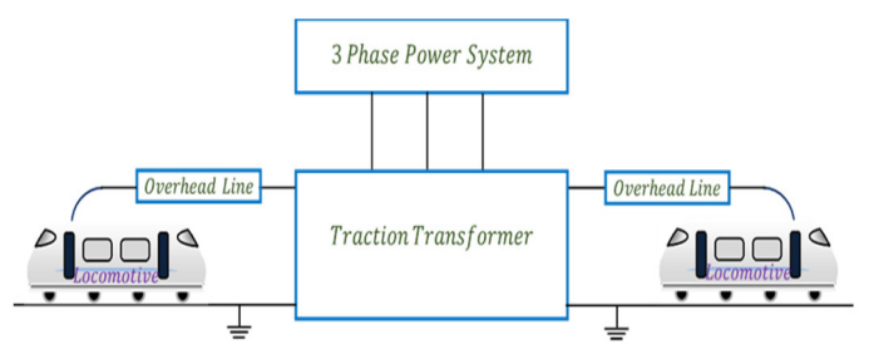

Figure 5: Structure of Traction Power System in High Speed Railway

The electrified railway (locomotive) model has been developed by using PSCAD as shown below:

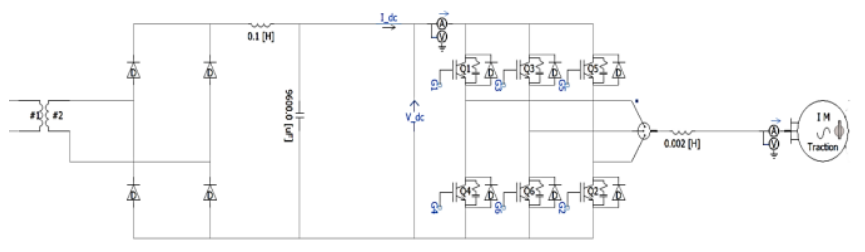

Figure 6: Locomotive Model in PSCAD

To simulate the model, $110 \mathrm{kV}$ utility power supply feeds the railway system through a $\mathrm{V} / \mathrm{V}$ transformer. Then, $\mathrm{V} / \mathrm{V}$ transformer converts the $110 \mathrm{kV}$ three phase voltage into $25 \mathrm{kV}$ two single-phase and it injects power to the catenary system. Each phase of V/V transformer feeds different side of catenary system [14]. The catenary system impedance is assumed 0.169 $+\mathrm{j} 0.432 \Omega / \mathrm{km}$ at $60 \mathrm{~Hz}$. The system is assumed to have two equal load on different catenary sides at the same distance. The distance from one train to substation is assumed $10 \mathrm{~km}$, that means the distance between two train is $20 \mathrm{~km}$.

The simulation circuit has been constructed based on the operation characteristic and the main circuit of the electric 
International Journal of Engineering Research and Technology. ISSN 0974-3154, Volume 13, Number 10 (2020), pp. 3020-3028

(C) International Research Publication House. https://dx.doi.org/10.37624/IJERT/13.10.2020.3020-3028

locomotive as shown below:

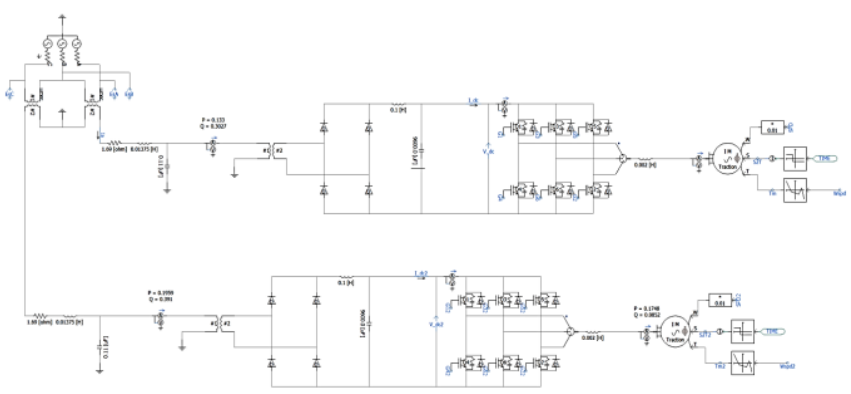

Figure 7: An overview of simulation circuit

The first part is the utility grid which is represented by a threephase voltage source which is equivalent of the network connected to a substation. Then, second part is the electric traction system which is starting with $\mathrm{V} / \mathrm{V}$ transformer (3-phase to two single phases as explained) which is stepping down the voltage from $110 \mathrm{kv}$ to $25 \mathrm{kv}$.

Then, the catenary feeds the power supply of the electric locomotive that is the independent bogie with three traction motors in parallel supplied by a main rectifier. Using asymmetric bridge rectifier circuit, implement phased regulating, realize the constant current constant speed control of drawing speed characteristics [8].

The control process of the inverter side is accomplished by controlling the firing angle of the thyristor or IGBT in order to control the voltage which will be applied on the traction, control circuit for IGBT as shown below.

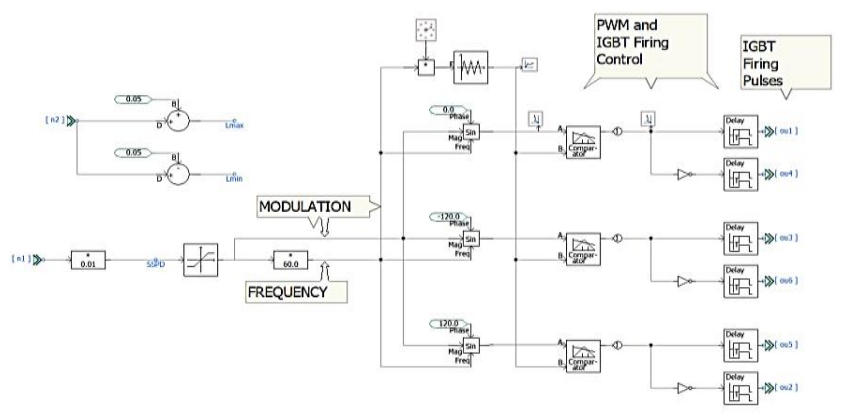

Figure 8: Control circuit for thyristor firing angle

The reference voltage is a three-phase sinusoidal waveform (reference) and the speed reference is the input for the drive system, therefore the reference speed defines the frequency of the three-phase sinusoidal waveform. Then, the waveform is compared to a sawtooth waveform to generate pulses for the inverter switches and the switching converts a dc voltage to a chapped ac voltage. The ac voltage drives the induction motor so that it will rotate at the same speed that is defined by the speed reference.

In this simulation, different situations (different speeds \& motor modes) will be simulated.

\section{SIMULATION RESULTS}

As shown below, the voltage characteristic of utility network (primary side)

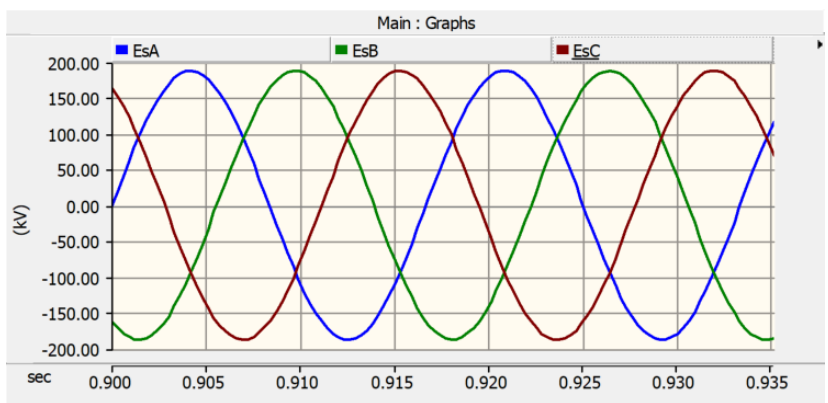

Figure 9: Voltage characteristic of utility network

the current characteristic of utility network (primary side)

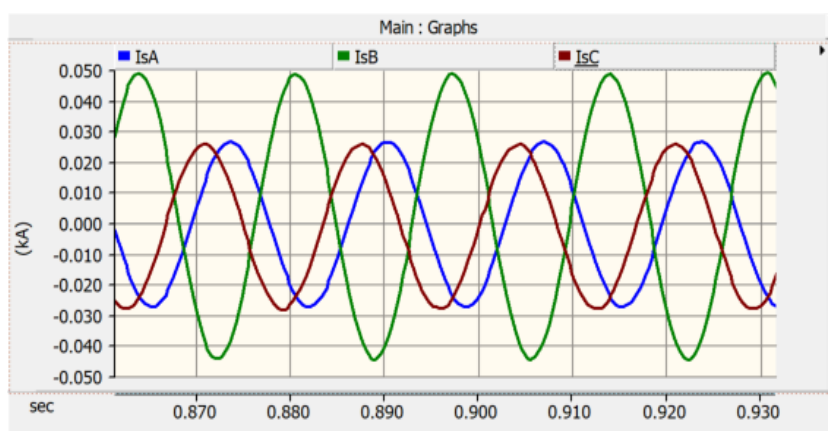

Figure 10: Current characteristic of utility network

The waveform in Figure 10, it can be seen that the amplitude and phase of A, B, C three-phase current are not symmetrical and the amplitude of one phase is obviously smaller than the other two phases.

As shown below, the DC voltage after converting single phase AC input to a stable DC link bus voltage

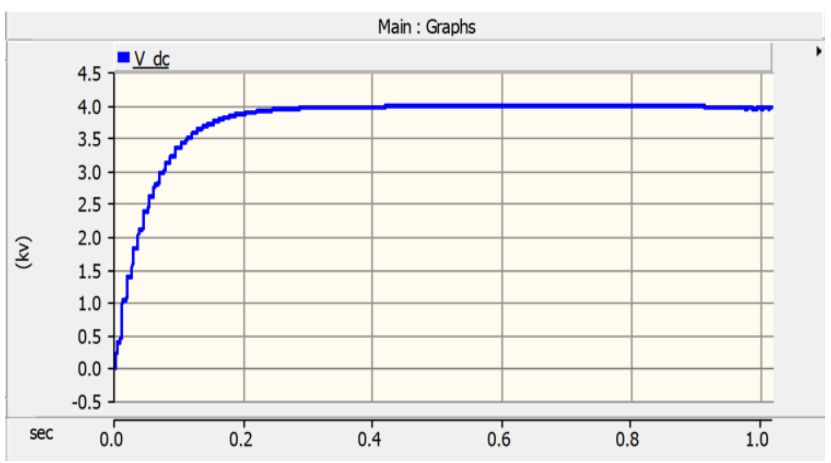

Figure 11: DC voltage

As explained previously in control circuit, the generated pulses of firing angles according to the required speed of induction motor 


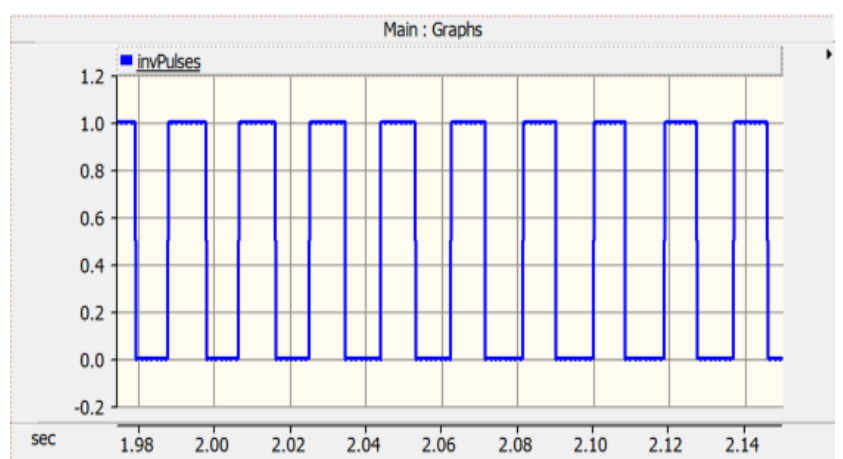

Figure 12: Pulse waveform for firing angles of thyristor

In this simulation, different speeds from 0 to nominal speed will be simulated in multiple cases as shown below:

Case 1: Starting Point ( $\mathrm{f}=0.9 \mathrm{~Hz}, \mathrm{U}=53 \mathrm{v}, \mathrm{I}=382 \mathrm{~A}$ )

The characteristic of Power and Reactive Power

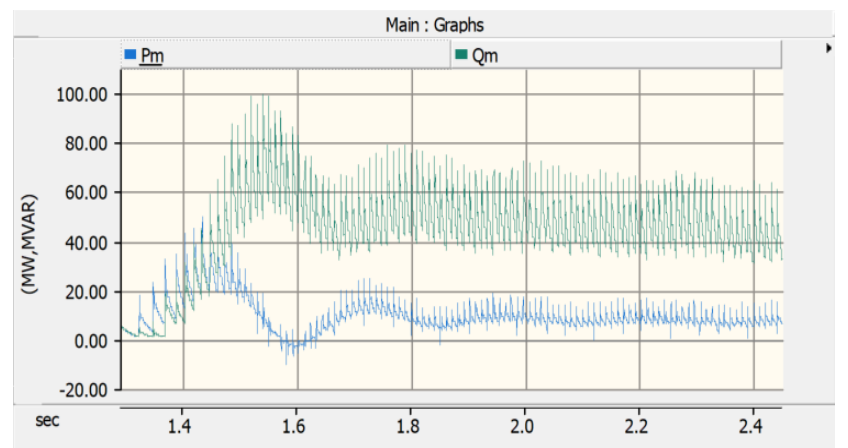

Figure 13: Power \& Reactive Power

By taking the Fast Fourier Decomposition (FFT) for the utility harmonic current [10].

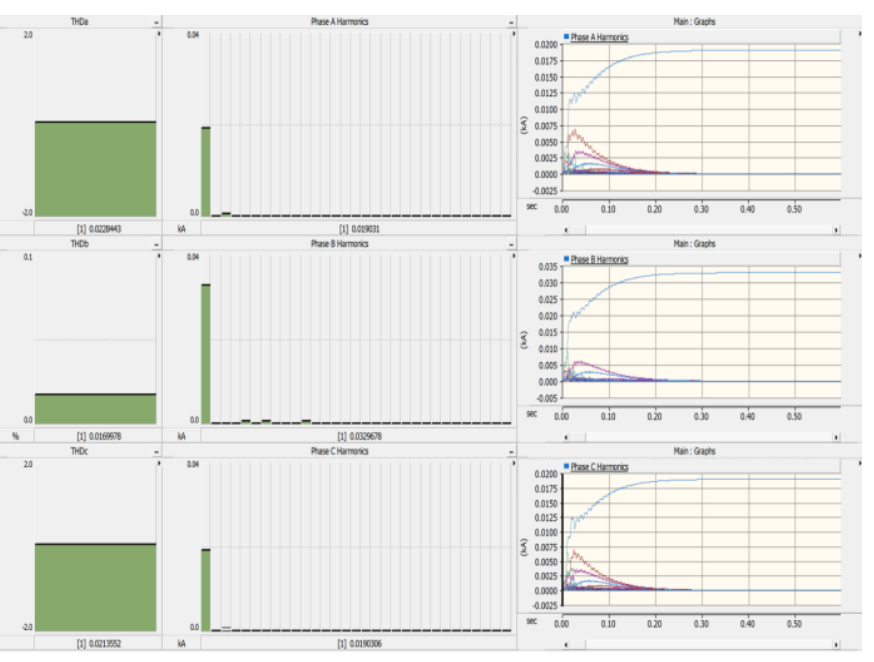

Figure 14: Current Harmonic
Case 2: Saddle Point $(\mathrm{f}=65.8 \mathrm{~Hz}, \mathrm{U}=1988 \mathrm{v}, \mathrm{I}=383 \mathrm{~A})$

The characteristic of Power and Reactive Power

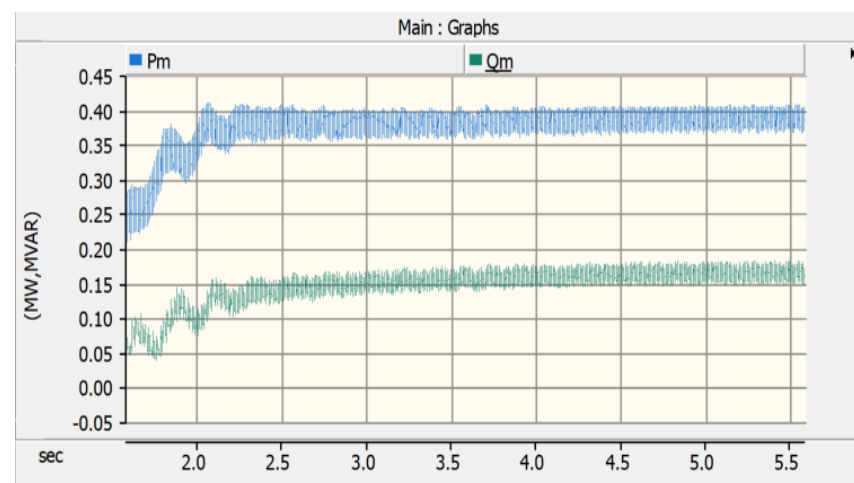

Figure 15: Power \& Reactive Power

By taking the Fast Fourier Decomposition (FFT) for the utility harmonic current

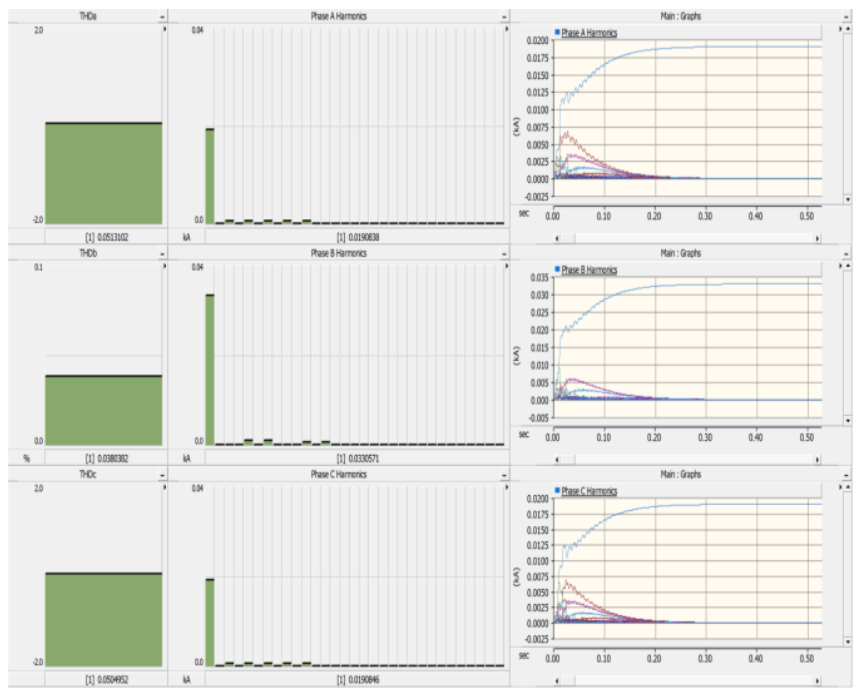

Figure 16: Current Harmonic

Case 3: Type Point ( $\mathrm{f}=72.8 \mathrm{~Hz}, \mathrm{U}=2183 \mathrm{v}, \mathrm{I}=348 \mathrm{~A})$

The characteristic of Power and Reactive Power

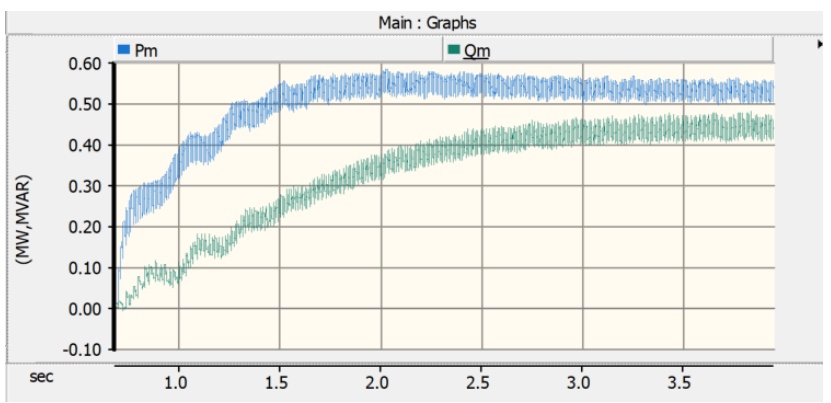

Figure 17: Power \& Reactive Power

By taking the Fast Fourier Decomposition (FFT) for the utility harmonic current 
International Journal of Engineering Research and Technology. ISSN 0974-3154, Volume 13, Number 10 (2020), pp. 3020-3028

(C) International Research Publication House. https://dx.doi.org/10.37624/IJERT/13.10.2020.3020-3028

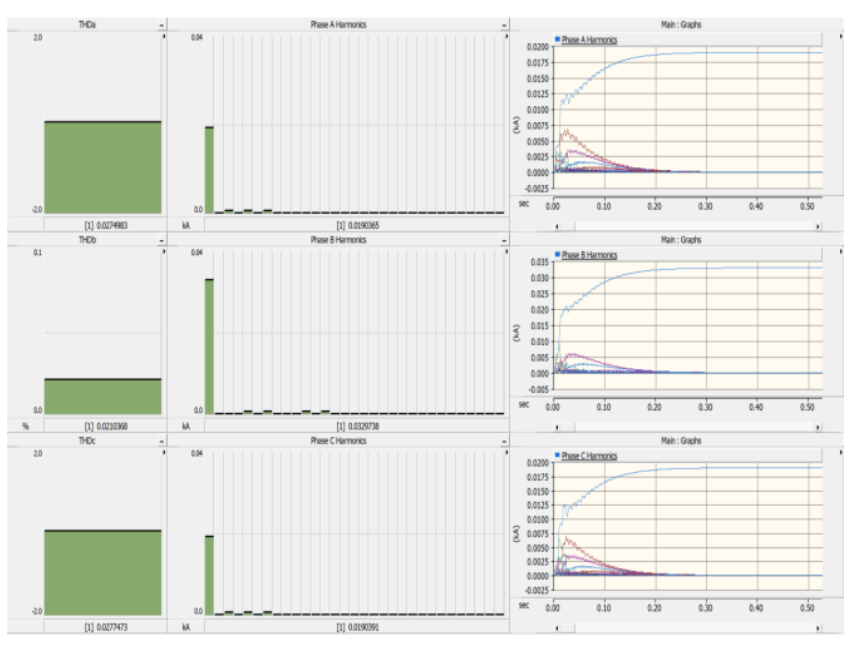

Figure 18: Current Harmonic

Case 4: Pull-Out Point ( $\mathrm{f}=153 \mathrm{~Hz}, \mathrm{U}=2183 \mathrm{v}, \mathrm{I}=376 \mathrm{~A}$ )

The characteristic of Power and Reactive Power

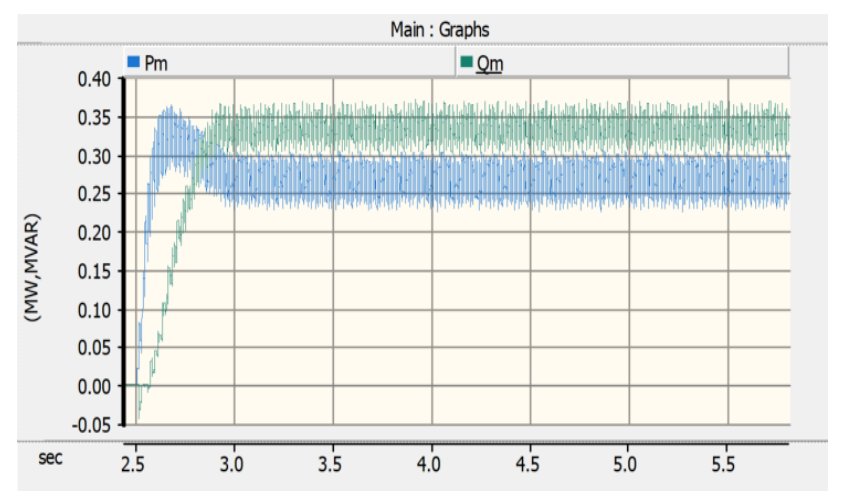

Figure 19: Power \& Reactive Power
By taking the Fast Fourier Decomposition (FFT) for the utility harmonic current

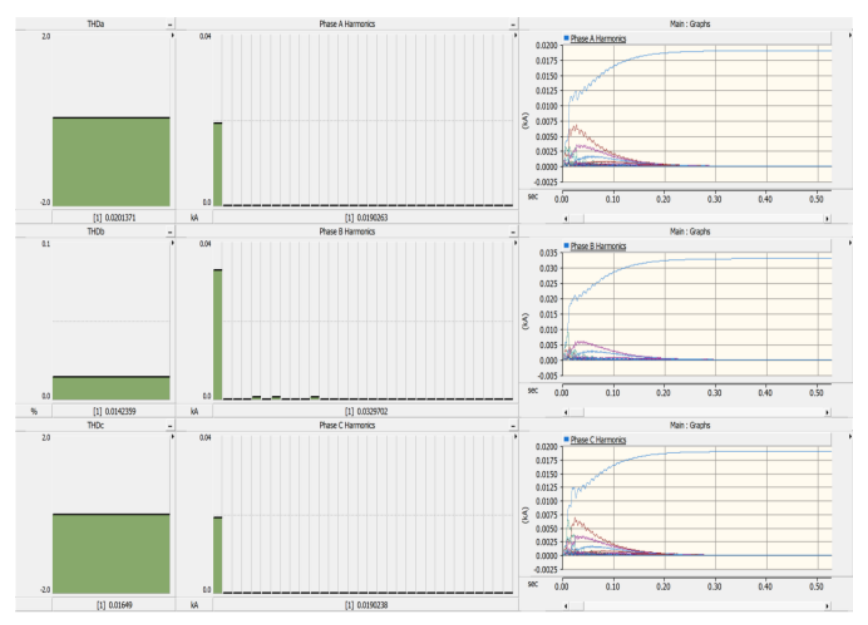

Figure 20: Current Harmonic

Here is the summary of current harmonics results of the simulated cases as shown in Table 1

Table 1: Current Harmonics in Three-Phase Power Grid

\begin{tabular}{|c|c|c|c|c|c|c|c|c|}
\hline \multicolumn{2}{|c|}{ Harmonics Order } & \multirow{2}{*}{$\frac{\mathbf{1}^{\text {st }}(\%)}{1.903}$} & \multirow{2}{*}{$\frac{3^{\text {rd }}(\%)}{0.020}$} & \multirow{2}{*}{$\begin{array}{c}\mathbf{5}^{\text {th }}(\%) \\
0.019\end{array}$} & \multirow{2}{*}{$\frac{7^{\text {th }}(\%)}{0.018}$} & \multirow{2}{*}{$\begin{array}{c}\mathbf{9}^{\text {th }}(\%) \\
0.016\end{array}$} & \multirow{2}{*}{$\frac{11^{\text {th }}(\%)}{0.014}$} & \multirow{2}{*}{$\begin{array}{c}\text { THD (\%) } \\
2.28\end{array}$} \\
\hline & Phase A & & & & & & & \\
\hline$\underset{\infty}{\approx}$ & Phase B & 3.297 & 0.001 & 0.033 & 0.029 & 0.002 & 0.023 & 1.70 \\
\hline & Phase C & 1.903 & 0.019 & 0.018 & 0.017 & 0.015 & 0.013 & 2.14 \\
\hline \multirow{3}{*}{$\underset{\mho}{\tilde{\mho}}$} & Phase A & 1.908 & 0.053 & 0.048 & 0.042 & 0.034 & 0.026 & 5.13 \\
\hline & Phase B & 3.306 & 0.001 & 0.084 & 0.072 & 0.001 & 0.046 & 3.80 \\
\hline & Phase C & 1.908 & 0.053 & 0.048 & 0.041 & 0.034 & 0.026 & 5.05 \\
\hline \multirow{3}{*}{ లు } & Phase A & 1.904 & 0.026 & 0.024 & 0.022 & 0.019 & 0.016 & 2.73 \\
\hline & Phase B & 3.298 & 0.000 & 0.042 & 0.038 & 0.000 & 0.028 & 2.08 \\
\hline & Phase C & 1.904 & 0.026 & 0.024 & 0.022 & 0.019 & 0.016 & 2.72 \\
\hline
\end{tabular}


International Journal of Engineering Research and Technology. ISSN 0974-3154, Volume 13, Number 10 (2020), pp. 3020-3028

(C) International Research Publication House. https://dx.doi.org/10.37624/IJERT/13.10.2020.3020-3028

\begin{tabular}{|c|c|c|c|c|c|c|c|c|}
\hline \multirow{3}{*}{ 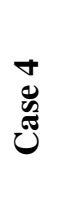 } & Phase A & 1.903 & 0.018 & 0.017 & 0.016 & 0.014 & 0.012 & 2.01 \\
\hline & Phase B & 3.297 & 0.004 & 0.027 & 0.024 & 0.003 & 0.020 & 1.42 \\
\hline & Phase C & 1.902 & 0.014 & 0.013 & 0.013 & 0.011 & 0.010 & 1.65 \\
\hline \multirow{3}{*}{$\begin{array}{l}n \\
0 \\
\tilde{z} \\
\tilde{W}\end{array}$} & Phase A & 1.902 & 0.012 & 0.012 & 0.011 & 0.010 & 0.009 & 1.48 \\
\hline & Phase B & 3.294 & 0.001 & 0.020 & 0.019 & 0.000 & 0.016 & 1.13 \\
\hline & Phase C & 1.902 & 0.012 & 0.012 & 0.011 & 0.010 & 0.009 & 1.44 \\
\hline
\end{tabular}

Case 5: Max Point ( $\mathrm{f}=124.8 \mathrm{~Hz}, \mathrm{U}=2183 \mathrm{v}, \mathrm{I}=354 \mathrm{~A})$

The characteristic of Power and Reactive Power

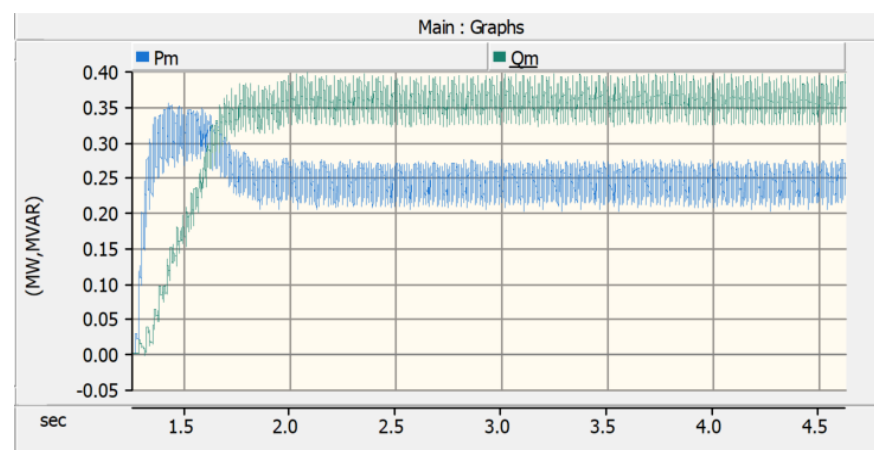

Figure 21: Power \& Reactive Power

By taking the Fast Fourier Decomposition (FFT) for the utility harmonic current

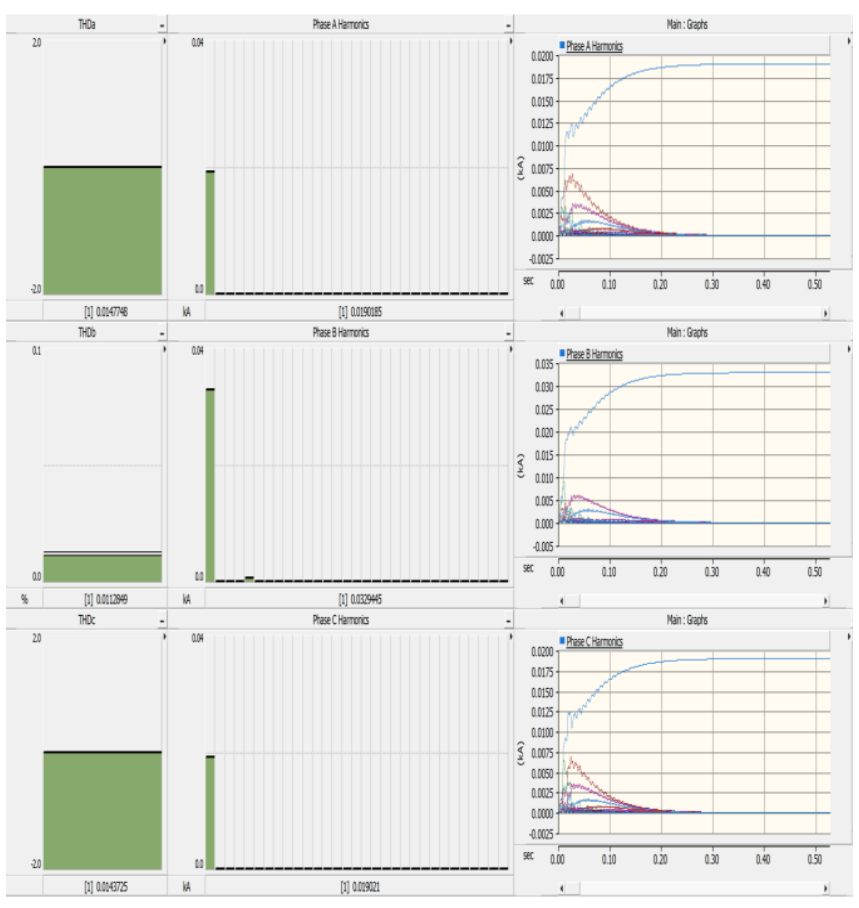

Figure 22: Current Harmonic

\section{ANALYSIS AND DISCUSSION}

As it is has simulated as a simplified railway power system of multi scenarios of induction motors (5 cases), it is clear that power quality disturbances caused by non-linear loads that connected to the three-phase power grid.

Due to the non-linear loads are symmetrical on both sides of the transformer, the harmonic spectrum is substantially equal on each of phase $A$ and phase $C$, and the harmonic of phase $B$ which is the common between the two sides of the transformer has a greater value than the other two phases.

From the harmonic current wave spectrum in the above figures, it is obvious that at the PCC the odd harmonics are the dominant $\left(3^{\text {rd }}, 5^{\text {th }}, 7^{\text {th }}, 9^{\text {th }}\right.$ and $\left.11^{\text {th }}\right)$ and it's clear that phase B current is substantially not equal to phases A \& C currents. In this case which is totally imbalance because the current will flow only through the arms on $25 \mathrm{KV}$ side of the transformer and a large amount of (NSCs) have been generated due to the unsymmetrical load on the both sides of the transformer and this affected each phases and polluted the power system by injecting a large amount of harmonics into the system.

In practice and in the real world, if the number of locomotives is increased, then the harmonic and negative sequence effects will be further increased. In addition, a various types of voltage transient swells, sags and overvoltage, etc are depending on the characteristics of the power supply system and loads and also some cases referred to the way of power is drawn from traction line supply through the sliding contact of pantograph and not to mention that the variability of the traction load due to trains timetable and operating conditions is also a relevant source of multi power quality disturbances.

\section{HARMONIC MITIGATION}

Harmonic mitigation is majorly achieved by harmonic filters. Harmonic filters are used to mitigate the injection of harmonic currents flowing from harmonic generating load to into upstream network as PCC. The harmonic filter mitigation could be achieved by either individual compensation at electric locomotive itself or total compensation at the substation. Different rating of electric locomotive operating at the same time on the same traction and the effective location for harmonic filter is $25 \mathrm{kV}$ side of the traction substation. 


\section{CONCLUSION}

Through a large amount of data collection, a regional power grid is selected as the analysis object to extract the typical public power grid model and combined with the typical traction power supply system to carry out comprehensive analysis.

In addition, in the actual operation, the characteristics of traction transformers with different connection modes under different operation modes can be considered comprehensively, and reasonable dispatch can be made to reduce the negative sequence effect on the power grid. For example, in the case of $\mathrm{V} / \mathrm{V}$ traction transformer connected to the same system bus, it may be considered to allow connection of traction transformer in operation to ensure that the load of the two power supply arms is similar, in order to reduce the negative sequence effect.

This paper studies and analyzes the different operation modes of traction power supply system and public power grid. Because of the typicality of the extracted power grid, the analysis results can be used as a reference for the analysis of harmonic and negative sequence effects related to the power grid in similar traction load, and can be used for the selection of power and railway departments. Also, it provides a basis for the research of electrical mode and system power quality analysis.

\section{ACKNOWLEDGMENT}

The authors gratefully would like to acknowledge the support and help that have been provided by King Abdulaziz University.

\section{REFERENCES}

[1] R. Dugan, M. McGranaghan, H. Wayne Beaty and S. Santoso, "Electrical Power Systems Quality", $3^{\text {rd }}$ edition, Ch.1.

[2] L. Barros, M. Tanta and A. Martins, "STATCOM Evaluation in Electrified Railway Using V/V and Scott Power Transformers", 2019.

[3] Kingdom of Saudi Arabia, Ministry of Transport, 2020, Vision and Mision, https://www.mot.gov.sa

[4] S. Gazafrudi, A. Langerudy, E. Funch, K. Al-Haddad, "Power Quality issues in Railway Electrification: A Comprehensive Perspective", IEEE Trans., 2015.

[5] M. Tanta, V. Monteiro, T. Sousa, A. Martins and J. Afonso, "Power Quality Phenomena in Electrified Railways: Conventional and New Trends in Power Quality Improvement toward Public Power Systems", IEEE, 2018.

[6] Gao Lin, Xu Yonghai, Xiao Xiangnin, Jiang Peisi and Zhang Yunyan, "Simulation Model and Harmonic Analysis of SS6B Electric Locomotive Based on PSCAD/EMTDC”, IEEE, 2008.

[7] A. Elagab, I. El-Amin and A. Mohammed, "The Power Quality issues Due To connecting an Electric Train To a Power Supply System”, IEEE, 2018.

[8] X. Jia, Zhe Liu, "Modeling and Simulation for the ACDC Electric Locomotive”, IEEE, 2015.
[9] A. Tabakhpour, Andrea Mariscotti and M. Abolhassani, "Power Quality Conditioning in Railway Electrification: A Comparative Study”, IEEE, 2015.

[10] Andrea Mariscotti, "Measuring the Power Quality in Electric Traction Systems”, IEEE, 2010.

[11] Majid Zare, Ali Varjani, S. Dehghan, Saeed Kavehei, "Power Quality Compensation and Power Flow Control in AC Railway Traction Power Systems", IEEE, 2019.

[12] Gao Lin, Xu Yonghai, Xiao Xiangnin, J. Peisi, Z. Yunyan, "Simulation Model and Harmonic Analysis of SS6B Electric Locomotive Based on PSCAD/EMTDC", IEEE, 2008.

[13] Hanmin Lee, Sehchan Oh, Gildong Kim, Cheonheon An, "A Study on the Equivalent Conductor Representation of AC Electric Railway System”, IEEE, 2009.

[14] Hu Guihua, Chen Weirong, Li Yankun, Zhang Yang, "Simulation of Traction Transformer Based on PSCAD/EMTDC”, IEEE, 2011.

[15] P. Wang, Z. Wang, Y. Li, F. Li, Bonan An and Bin Xie "An Asymmetrical Connection Balance Transformer Based Power Quality Control System for Electrical Railway", IEEE, 2017. 